\title{
Estimation of Vegetation Aerodynamic Roughness of Natural Regions Using Frontal Area Density Determined from Satellite Imagery
}

\author{
by
}

\author{
Michael F. Jasinski ${ }^{1}$ \\ NASA Goddard Space Flight Center \\ Hydrological Science Branch, Code 974 \\ Greenbelt, MD 20771
}

and

\author{
Richard Crago 2 \\ Department of Civil and Materials Engineering \\ University of Illinois at Chicago
}

Chicago, IL 60607-7023

1. Corresponding author. Fax: 1-301-614-5808; e-mail: Michael.F.Jasinski.1@gsfc.nasa.gov 2. Fax: 1-312-996-2426; e-mail: crago@uic.edu 


\begin{abstract}
Parameterizations of the frontal area index and canopy area index of natural or randomly distributed plants are developed, and applied to the estimation of local aerodynamic roughness using satellite imagery. The formulas are expressed in terms of the subpixel fractional vegetation cover and one non-dimensional geometric parameter that characterizes the plant's shape. Geometrically similar plants and Poisson distributed plant centers are assumed. An appropriate averaging technique to extend satellite pixel-scale estimates to larger scales is provided.
\end{abstract}

The parameterization is applied to the estimation of aerodynamic roughness using satellite imagery for a $2.3 \mathrm{~km}^{2}$ coniferous portion of the Landes Forest near Lubbon, France, during the 1986 HAPEX-Mobilhy Experiment. The canopy area index is estimated first for each pixel in the scene based on previous estimates of fractional cover obtained using Landsat Thematic Mapper imagery. Next, the results are incorporated into Raupach's $(1992,1994)$ analytical formulas for momentum roughness and zero-plane displacement height. The estimates compare reasonably well to reference values determined from measurements taken during the experiment and to published literature values. The approach offers the potential for estimating regionally variable, vegetation aerodynamic roughness lengths over natural regions using satellite imagery when there exists only limited knowledge of the vegetated surface.

Keywords: Canopy area index; Aerodynamic roughness; Remote sensing; Coniferous forest 


\section{Introduction}

Most model parameterizations of the surface momentum, sensible heat and latent heat fluxes, and many field and remote sensing techniques to measure them, rely on MoninObukhov similarity theory (e.g., Brutsaert, 1982; Stull, 1988). In the case of momentum, the similarity equation is expressed,

$$
u(z)=u_{*} k^{-1}\left[\ln \left(\frac{z-d_{o}}{z_{o}}\right)-\psi(\zeta)\right]
$$

where $u(z)$ is the surface layer wind speed at height $z, u *$ is the friction velocity, $k$ is von Karman's constant, and $\psi(\zeta)$ is the adjustment function due to stability. The momentum roughness length, $\mathrm{z}_{\mathrm{O}}$, is conceived as the zero velocity intercept of the vertical mean wind profile. The zero plane displacement height, $\mathrm{d}_{\mathrm{o}}$, is an elevation adjustment due to the conceptual vertical shift of the logarithmic profile in the presence of the roughness elements. Analogous similarity expressions are used for the sensible heat flux in terms of $z_{\mathrm{Oh}}$, the roughness length for sensible heat, and the latent heat flux in terms of $z_{O V}$, the roughness length for water vapor.

Numerical atmospheric simulation models used today for short-term operational weather forecasting including mesoscale models, or long-term climate analysis including general circulation models, employ some form of the above similarity equations. In order to run the models, roughness lengths are prescribed for each grid box in the domain prior to the simulation. However, since roughness data are not readily available at that resolution, values are assigned by associating roughness with vegetation type or land classification using look-up tables (e.g., Grell et. al., 1994). In the case of most operational general circulation models, $\mathrm{z}_{\mathrm{O}}, \mathrm{z}_{\mathrm{O}}$, and $\mathrm{z}_{\mathrm{OV}}$ are assigned the same value despite evidence to the 
contrary (e.g. Brutsaert and Sugita, 1992). The method usually involves the use of climatic land classification values that vary only on a seasonal basis but do not change from year to year.

The reason for the above approach lies in the difficulty in estimating roughness. Theoretically, $z_{O}$ and $d_{O}$ are independent of flow and only a function of the geometry of the surface (Brutsaert, 1982; Monteith and Unsworth, 1990). While analytical formulas and numerical studies have been presented based on drag expressions (e.g. Lettau, 1969; Mason, 1988; Seginer, 1974; Shaw and Pereira, 1982; Raupach, 1992, 1994, Wooding et. al., 1973; see summary by Brutsaert, 1982), they require knowledge of mean surface characteristics such as height, frontal area, surface density, and surface geometry. For vegetated surfaces in particular, key variables are the mean canopy height, frontal surface area and the mean plant density. Unfortunately, those characteristics are generally unknown, especially for natural regions where plants are randomly dispersed, that precludes application of the above formulas.

Practically, $z_{O}$ and $d_{0}$ for various land surface geometries are best determined from sitespecific field experiments from the analysis of flux-profile measurements during neutral conditions, a method that requires substantial investment in manpower, time, and instrumentation. Over time, values have been tabulated for a wide range of representative surfaces (e.g., Brutsaert, 1982; Stull, 1988).

Improved characterization of the land surface, using satellite imagery, may lead to improved estimates of aerodynamic roughness lengths and significant progress over present applications. Over the past two decades, satellite remotely sensed observations of reflected visible and near-infrared solar energy have been used to estimate an increasingly greater number of plant attributes such as leaf area index (LAI), biomass, and fractional cover. 
Most techniques involve correlation with empirical indices constructed from multispectral bands (e.g. Perry and Lautenschlager, 1984; Tucker et. al., 1983; Asrar et. al., 1984; Huete, 1988), although sensitivity studies have shown their limitations (Jasinski, 1990; Huete and Liu, 1994). Other investigators have modeled the radiation physics through the plant canopy (e.g. Ross, 1981; Myneni et al., 1989; also see summary in Asrar, 1989). However, that approach is often constrained by the relatively large number of model parameters, especially in heterogeneous regions.

The inversion of geometric canopy reflectance models using satellite multispectral imagery has provided a practical approach for investigating regional vegetation variability, and a possible avenue for characterizing roughness. Plants are conceived as randomly distributed, three-dimensional elements superposed on a flat surface ( $\mathrm{Li}$ and Strahler, 1985), with only a few key bulk plant parameters, often in non-dimensional form (Jasinski and Eagleson, 1990). The approach has successfully provided estimates of fractional cover and LAI over forested and semiforested landscapes using satellite imagery ( $\mathrm{Li}$ and Strahler, 1985; Franklin and Strahler, 1988; Jasinski, 1996). It is especially applicable in natural regions where the canopy cover often is spatially random. Since the method relies on the characterization of the bulk canopy geometry, it offers an opportunity for estimating the local aerodynamic roughness that also is a function of those same physical properties.

\section{Background}

\subsection{Parameterization of $z_{O}$ and $d_{o}$ in terms of plant frontal area density}

One analytical approach for parameterizing the local momentum roughness length in terms of geometric canopy parameters is that by Raupach $(1992,1994)$. Using dimensional analysis and physical hypotheses on the partitioning of surface stress, he derived an expression for $z_{O} / \mathrm{h}$ in terms of the drag on the roughness elements and on the underlying 
surface. The parameterization provides "a relatively simple unified theory" (Mahrt, 1996) for turbulent transport within canopies.

A key plant parameter is the frontal area index or density, $\lambda$, defined as the ratio of frontal area of roughness elements, from the mean wind direction, per unit ground area. For solid elements,

$$
\lambda=\frac{\mathrm{nbh}}{\mathrm{S}}
$$

where bh represents the frontal area (breadth $\mathrm{x}$ height) of a single roughness element, $\mathrm{n}$ is the number of elements, and S is the total ground area. Raupach (1994) later determined it convenient to replace $\lambda$ with the canopy area density or index, $\Lambda$, or the total single sided area of all the canopy elements per unit ground area. It differs from the LAI in that the latter usually includes only the green leaf area, while $\Lambda$ includes all canopy elements that absorb momentum. For isotropically oriented elements, the relationship between the two is approximately $\Lambda=2 \lambda$ (Raupach, 1994).

Raupach's (1994) aerodynamic roughness equations are expressed

$$
\frac{\mathrm{z}_{\mathrm{o}}}{\mathrm{h}}=\left(1-\frac{\mathrm{d}_{\mathrm{o}}}{\mathrm{h}}\right) \exp \left(-\kappa \frac{\mathrm{U}_{\mathrm{h}}}{\mathrm{u}_{*}}-\Psi_{\mathrm{h}}\right)
$$

where $U_{h}$ is the velocity at the top of the canopy, $\Psi_{h}$ is a velocity profile adjustment, and the remaining terms are as defined above. The ratio of $u * / U_{h}$ is expressed 


$$
\frac{\mathrm{u}_{*}}{\mathrm{U}_{\mathrm{h}}}=\min \left[\left(\mathrm{C}_{\mathrm{s}}+\mathrm{C}_{\mathrm{R}} \frac{\Lambda}{2}\right)^{\frac{1}{2}} \exp \left(-\frac{\mathrm{c} \Lambda}{4} \frac{\mathrm{U}_{\mathrm{h}}}{\mathrm{u}_{*}}\right),\left(\frac{\mathrm{u}_{*}}{\mathrm{U}_{\mathrm{h}}}\right)_{\max }\right]
$$

where $C_{S}$ and $C_{R}$ are the drag coefficients for the ground and roughness elements, respectively, $c$ is an empirical coefficient related to wake spreading, and $\left(u * / U_{h}\right)_{\max }$ is the maximum observed ratio when the flow begins to skim over the top of the canopy instead of penetrating to the surface. Raupach (1994) developed an empirical expression for the displacement height, or

$$
1-\frac{d_{0}}{h}=\frac{1-\exp \left[-\left(c_{d 1} \Lambda\right)^{\frac{1}{2}}\right]}{\left(c_{d 1} \Lambda\right)^{\frac{1}{2}}}
$$

where $c_{\mathrm{d} 1}$ is derived from a wide range of laboratory and field data. The equation is designed to approach the proper limits as $\Lambda$ approaches zero and infinity.

\subsection{Geometric canopy model for natural or randomly distributed plants}

The geometric model, shown in Figure 1, is characterized by both its shape and its spatial distribution. The canopy itself is represented as three-dimensional, geometric elements positioned on a flat horizontal surface. The plants are assumed to be geometrically similar, that is, the individual canopies within a plant stand, although of different size, are considered to be one geometric shape with a constant width to height ratio, $\mathrm{D} / \mathrm{H}$. Various common shapes such as cones, cylinders and ellipsoids can be employed as shown in Table 1. 
Spatially, the model assumes a random horizontal plant distribution. Plant centers of natural regions are most often described by the Poisson process (Diggle, 1983; Whittaker, 1975). Further, plants with large diameters or situated in dense stands tend to overlap one another. Consequently, the mean vertically projected canopy area per unit ground area, or the fractional canopy cover, $\mathrm{m}$, is mathematically expressed after the probability work by Kellerer (1983), or

$$
m=1-\exp \left(-A_{t} \rho\right)
$$

where $A_{t}$ is the mean vertically projected canopy area of a single tree, and $\rho$ is the spatial Poisson density or,

$$
\rho=n / A_{p}
$$

where $A_{p}$ is the unit area, in this case the area of the satellite pixel.

A final characteristic of the geometric model, necessary for remote sensing, is the parameterization of subpixel fractional ground shadow cast by the canopies in terms of their geometric shape, spatial density, and the solar zenith angle. It was previously shown (Jasinski, 1990) using Equation (6) that for any Poisson distributed plant, a parameterization of the subpixel ground shadow exists for satellite pixels greater than several tens of meters, or

$$
\mathrm{g}_{s}=1-\mathrm{m}-(1-\mathrm{m})^{\eta+1} \text {, }
$$


where $\mathrm{m}$ is the total fractional canopy cover in a given pixel, $\mathrm{g}_{\mathrm{s}}$ is the total fractional ground shadow in a pixel, and $\eta$ is a non-dimensional, solar-geometric similarity parameter defined as the ratio of the mean shadow area cast by a single tree, $A_{S}$, to its mean projected canopy area or,

$$
\eta=\frac{A_{s}}{A_{t}}
$$

Using $\eta$ in this non-dimensional form allows one to generalize the shadow parameterization for any canopy geometry. Analytical expressions for $\eta$ for several geometrical shapes are shown in Table 1. The expressions are developed in terms of the solar zenith angle, $\theta$, and the ratio of some maximum plant width to plant height, or D/H. Qualitatively, large $\eta$ represents tall, bulky plants that cast large shadows while small $\eta$ represents thin short plants. The $\eta$ can be estimated from Table 1 or directly from aerial photographs during clear-sky conditions.

\section{Parameterization of frontal and canopy area indices for natural regions 3.1 Frontal area index for spatially random solid geometric canopies}

In order to apply Raupach's equations to satellite imagery, it is first necessary to develop a subpixel parameterization of the frontal area or canopy area index. Since the scale of the plant canopy (order of several meters) is much smaller than the scale of the typical satellite pixel (order of tens of meters or greater), variations in frontal density occur at the subpixel level. Consequently, a parameterization is required that relates frontal density in terms of a subpixel quantity that can be measured from satellites, such as fractional vegetation cover. Since the method will be applied mostly to natural or undisturbed regions, 
it is also desirable to incorporate the spatially random nature of the plant canopy in the formulation.

The present approach will follow the method used to parameterize subpixel shadows described above. The starting point is the equivalent definition of the frontal area density, $\lambda$, or

$$
\lambda=\frac{n A_{f}}{A_{p}}
$$

where $A_{f}$ is the mean frontal area of an individual plant or roughness element. The nondimensional frontal area similarity parameter, $v$, is now introduced as the ratio of the mean frontal area of an individual plant to the mean vertically projected canopy area or

$$
v=\frac{A_{f}}{A_{t}}
$$

Physically, large $v$ represents tall plants with narrow canopies while small $v$ represents short plants with wide canopies. Theoretical expressions for $v$ have been derived for various geometric shapes in terms of the geometric similarity ratio described earlier, as shown in Table 1. Combining Equations (10) and (11) yields,

$$
\lambda=v \frac{\mathrm{nA}_{\mathrm{t}}}{\mathrm{A}_{\mathrm{p}}} .
$$

Assuming a Poisson horizontal distribution within each pixel, the combination of (6), (7) and (12) yields a subpixel parameterization for the frontal area index in terms of fractional cover and the non-dimensional quantity $v$, or 


$$
\lambda=-v \ln (1-\mathrm{m}) .
$$

\subsection{Canopy area index for spatially random solid geometric canopies}

The canopy area density is the total, single sided area of the canopy per unit ground area. For geometric solids, unlike leaf and branch elements, the assumption of isotropic components is not generally applicable. Therefore, the assumption that $\Lambda=2 \lambda$ can not exactly be applied except perhaps for certain (i.e. ellipsoidal) canopies. However, an expression for $\Lambda$ can be formulated in a similar manner to the frontal area index. The canopy area similarity parameter is first defined,

$$
\mathrm{N}=\frac{\mathrm{A}_{\mathrm{c}}}{\mathrm{A}_{\mathrm{t}}}
$$

where $A_{c}$ is the total exposed (i.e. outside) surface area of the geometrically shaped canopy. For consistency with Raupach's (1994) formulation for momentum roughness, the "singlesided" canopy area is defined as one-half the exposed surface area or $A_{c} / 2$. Using the same approach as in Equations (10) through (13) in Section 3.1 above, the subpixel canopy area index parameterization becomes,

$$
\Lambda=-\frac{N}{2} \ln (1-\mathrm{m})
$$


Expressions for $\mathrm{N}$ for various geometric shapes are provided in Table 1. For canopies conceptualized as solid geometric elements, the relation between the canopy area and frontal area indices is,

$$
\Lambda=\frac{N}{2 v} \lambda
$$

where $\Lambda=2 \lambda$ only when $\mathrm{N} / v=4$.

Equations (13) or (15) provide the essential link between the estimation of fractional cover using remote sensing, and Raupach's method for estimating aerodynamic roughness. They indicate that if the canopy frontal similarity parameter can be prescribed in geometric terms of $v$ or $\mathrm{N}$, then once fractional cover is known from the satellite analysis, the canopy frontal density required for Raupach's equation can be estimated for each satellite pixel.

A log-linear plot of the theoretical canopy area index versus fractional cover is provided in Figure 2. The figure is not specific to a particular canopy shape, but presented in nondimensional form, is applicable to any plant with Poisson distributed centers. It can be utilized in conjunction with any plant shape when configured in the non-dimensional form using the canopy area similarity parameter, N. A similar graph could be plotted for $\lambda$ versus $\mathrm{m}$.

The physical interpretation of Figure 2 can be explained as follows: For sparse canopies, that is fractional covers less than about 0.20 , the canopy area index increases roughly proportionally with increasing fractional cover, due to the behavior of $\ln (1-\mathrm{m})$ for small $\mathrm{m}$. Physically, this is due to the fact that there is little overlap among the canopies at such low horizontal densities. However, for large fractional covers, it takes an increasingly greater number of trees for each additional unit of canopy area due to increasing overlap 
among the dense trees. Consequently, the canopy area index increases less rapidly per unit increases in fractional cover at this higher range.

The use of the Table 1 in conjunction with Figure 2 provides a mechanism, at least

theoretically, to compare the canopy area indices of differently shaped roughness elements. For instance, roughness elements with a similarity shape of $\mathrm{N}=2$ and cover density $\mathrm{m}=0.6$ would theoretically possess the same canopy area index as roughness elements with a similarity shape of $\mathrm{N}=10$ and cover density $\mathrm{m}=0.16$.

In some cases, previous knowledge from the shadow analysis can be used in the estimation of $v$ or $N$. For example, knowledge of $\eta$ and the solar zenith angle can provide the ratio $\mathrm{D} / \mathrm{H}$ in order to estimate $v$ or $\mathrm{N}$.

\section{Characterization of aerodynamic roughness of the Landes Forest}

\subsection{Approach}

The estimation of aerodynamic roughness as presented herein is formulated as a threestep approach. First, the subpixel fractional canopy cover is estimated for each pixel in the scene. Second, the corresponding canopy area index for each pixel is estimated using the above formulas and fractional cover estimates. Third, the canopy area index is incorporated into Raupach's formulations in order to estimate roughness. Although other roughness formulas can be used, Raupach's seem the most straightforward. A simple averaging technique for the current problem is presented.

As indicated in the Introduction, techniques for the first step in estimating fractional cover using geometric modeling are well documented and therefore will not be repeated 
here. Thus, the present analysis will focus on the latter two steps where, building on previous work, they are applied to a region where published satellite-derived fractional cover estimates already exist.

\subsection{Estimation of subpixel fractional cover and leaf area}

One region that has received considerable attention is the Landes Forest near Lubbon, France, site of the June 1986 HAPEX-Mobilhy First ISLSCP Experiment (Andre et al, 1986). This portion of the Landes Forest is flat and dominated principally by maritime pine (Pinus Pinaster Aiton) stands with an understory consisting of bracken fern. Interspersed between the pine stands are shrub and agricultural lands comprising less than one-quarter of the total area.

Fractional cover estimates previously were made on a pixel by pixel basis at $30 \mathrm{~m}$ resolution for an approximately $2.3 \mathrm{~km}^{2}$ portion of the region using nadir viewing Landsat Thematic Mapper imagery (Jasinski, 1996). The frequency distribution of fractional cover is shown in Figure 3. The mean fractional cover of the total area was estimated to be 0.67 and the standard error was estimated at 0.056 .

The leaf area index of only the tree canopy, $\mathrm{LAI}_{\mathfrak{c}}$, without including the bracken understory, was estimated to be approximately 2.3 based on measurements at one tower site (Gash et al., 1989). Satellite-based measurements (Jasinski, 1996) for pixels within the 2.3 $\mathrm{km}^{2}$ Lubbon region possessing nearly complete canopy cover $(\mathrm{m} \sim 1)$ yielded a total leaf area index of both tree canopy and the bracken understory, or LAI, of about 3.1. Assuming the bracken typically possesses an LAI of about 1.0, the satellite estimates of total LAI are consistent with the $\mathrm{LAI}_{c}$ value observed by Gash et al. (1989). 


\subsection{Characterization of canopy geometric properties}

The canopy geometric properties required for the analysis were based only on the maritime pine, since it dominates over three-fourths of the region. The majority of the maritime pine stands in the Lubbon area were fairly mature, ranging in size with an average total height of about $20 \mathrm{~m}$ and an average density of approximately 430 stems ha- $^{-1}$ (Gash et al., 1989). Although no field measurements of the canopy geometry were made, analysis of aerial photographs indicate that the structure of the typical tree can be characterized as a bulky, conifer canopy situated on a long stem with a mean width, D, of approximately 5.1 m. From a geometric modeling perspective, the trees are best represented as cones on a post, shown in Table 1.

In order to proceed, the ratio $\mathrm{D} / \mathrm{H}$, where $\mathrm{H}$ is the vertical height of the canopy itself, and the height of the stem below the canopy, $\mathrm{h}_{\mathrm{s}}$, need to be estimated. Those values can not be determined directly from a single, nadir viewing aerial photograph. However, for this case their values can be estimated by knowledge of the shape of the tree and its shadow regime. Recalling previous estimates of $\eta=1.05$, and the solar zenith angle at time of overpass, $\theta=31.6^{\circ}$ (Jasinski, 1996), and assuming geometrically similar trees, the definition of $\eta$ from Table 1 becomes,

$$
\eta=1+\frac{1}{\pi}\left(\cot \chi-\frac{\pi}{2}+\chi\right)-\frac{2}{\pi}\left\{\cos ^{-1}(\mu)-\left[\mu\left(1-\mu^{2}\right)^{\frac{1}{2}}\right]\right\}
$$

where

$$
\chi=\sin ^{-1}\left(\frac{D}{H \tan \theta}\right)
$$

and

$$
\mu=\frac{h_{s}}{D} \tan \theta .
$$


Combining Equation (17) with the above limited information (i.e. $\mathrm{D}=5.1 \mathrm{~m}$, and $\mathrm{H}+\mathrm{h}_{\mathrm{s}}=$ $20 \mathrm{~m}$ ) yields estimates of $H=12.8 \mathrm{~m}, \mathrm{D} / \mathrm{H}=0.40$, and $h_{\mathrm{s}}=7.2 \mathrm{~m}$. A summary of all the Landes Forest site parameters is provided in Table 2.

\subsection{Estimation of canopy area index}

Continuing with the assumption of cones on a post, the value of $\mathrm{N}$ can be estimated using the formula in Table 1, or,

$$
\begin{aligned}
N & =1+\sqrt{1+\left(\frac{2 H}{D}\right)^{2}} \\
& =6.1 .
\end{aligned}
$$

Given N, Equation (15) is used to calculate the canopy area index for each pixel in the scene. The resulting frequency distribution over the entire scene is provided in Figure 4.

The mean canopy area index is computed by first averaging over the fractional cover density in order to account for scaling effects, or

$$
\bar{\Lambda}=-\frac{N}{2} \ln \left(1-\frac{1}{t} \sum_{i=1}^{t} m_{i}\right)
$$

where $t$ is the number of pixels, and $m_{i}$ is the fractional cover of an individual pixel. For the present case, the results yield $\bar{\Lambda}=3.4$ for the entire $2.3 \mathrm{~km}^{2}$ area. Following the same reasoning, it can be shown that the mean frontal area index is $\bar{\lambda}=1.8$. Those values 
seem reasonable and are consistent with analogous estimates for a pine forest (e.g. Garratt, 1977).

\subsection{Application of Raupach's formulation to estimate of $z_{o} / h$ and $d_{o} / h$ for the Landes Forest}

The roughness quantities, $z_{\alpha} / h$ and $d_{\alpha} / h$, theoretically can be estimated using $\Lambda$, Equations (3) through (5), and some knowledge of several constant parameters including $\mathrm{C}_{\mathrm{R}}, \mathrm{C}_{\mathrm{S}},\left(\mathrm{u} * / \mathrm{U}_{\mathrm{h}}\right)_{\max }, \mathrm{c}_{\mathrm{w}}$, and $\mathrm{c}_{\mathrm{d} 1}$. Raupach (1994) assumed global values for the constants based on field and wind tunnel data including forest sites, yielding the graphs in Figures 5

and 6. Applying those same global values without any special fitting for each pixel in the Lubbon Landes Forest, together with the estimated canopy area index, yields the frequency distribution of $z_{\delta} / \mathrm{h}$ shown in Figure 7 , and the frequency distribution of $d_{0} / \mathrm{h}$ shown in Figure 8.

In the present case, the forest area of $2.3 \mathrm{~km}^{2}$ is relatively small, and $\mathrm{h}$ has been assumed constant. The mean roughness, $\overline{z_{\sigma} / \mathrm{h}}$ can be approximated simply by

$$
\frac{\overline{z_{o}}}{h}=\exp \left[\sum_{i} f_{i} \ln \left(\frac{z_{o i}}{h}\right)\right]
$$

where $\mathrm{f}_{\mathrm{i}}$ is the frequency of $\mathrm{z}_{\mathrm{O}_{\mathrm{i}}} / \mathrm{h}$ from Figure 7 . Particularly in cases where $\mathrm{h}$ is not constant, a more sophisticated averaging procedure may be necessary.

Applying Equation (20) to the frequency distribution in Figure 7 yields $\overline{z_{0} / \mathrm{h}}=0.061$. This can be compared to the estimate obtained simply by applying the mean canopy area index (i.e. for $\bar{\Lambda}=3.4$ ) to Equations (3) and (5) that yields $\overline{z_{o} / \mathrm{h}}=0.062$. Thus, the 
averaging approach is not significant for the present case. Applying either approach to the displacement height yields a mean $\overline{\mathrm{d}_{\mathrm{O}} / \mathrm{h}}=0.79$. Thus, the results indicate a scene average of $\overline{z_{o}}=1.2 \mathrm{~m}$ and $\overline{\mathrm{d}_{\mathrm{o}}}=16.0 \mathrm{~m}$.

\section{Discussion}

\section{I Comparison with reference values}

Roughness lengths and displacement heights have been estimated for the Landes forest using at least two independent field methods. Parlange and Brutsaert (1989) analyzed highresolution radiosoundings under neutral stability over the region during the HAPEXMobilhy Experiment. They assumed that $d_{0}$ is approximately five times as large as $z_{0}$ [e.g., Brutsaert (1982), pages 113-116]. The analysis yielded $z_{o}=1.2 \mathrm{~m}$ and $\mathrm{d}_{\mathrm{o}}=6.0 \mathrm{~m}$. On the basis of Paeschke's (1937) estimate that $z_{0}=h / 7.5$, they concluded that the effective height of the roughness elements felt by the atmosphere was near $10 \mathrm{~m}$. This is intermediate between the average forest height of $20 \mathrm{~m}$ and the canopy heights in the clearings. During the same period, Gash et al. (1989) analyzed energy flux measurements made with eddy correlation equipment stationed on a tower $29 \mathrm{~m}$ above the ground. They estimated $\mathrm{z}_{\mathrm{o}}$ to lie at a height between $1.4 \mathrm{~m}$ and $2.4 \mathrm{~m}$, or approximately $1.9 \mathrm{~m}$, and they estimated that $\mathrm{d}_{\mathrm{o}}$ is about $75 \%$ of the mean tree height, or about $15 \mathrm{~m}$.

For canopy height taken to be the mean tree height of $20 \mathrm{~m}$, the Parlange and Brutsaert (1989) data yield $z_{\alpha} / h=0.06$ and $d_{\alpha} / h=0.30$, while the data of Gash et al. (1986) yield $z_{\alpha} / h=0.094$ and $d_{\alpha} / h=0.75$. The Raupach formulation in Figure 5 passes between these points for $z_{0} / h$. In fact, these points fall within the scatter of the data used to construct the original graph [Raupach, 1994]. The Raupach formulation for $d_{\mathcal{O}} /$ h on Figure 6 passes slightly above the Gash et al. (1986) point, but far above the Parlange and Brutsaert (1989) point. Also plotted on Figures 5 and 6 are the Parlange and Brutsaert (1989) data assuming 
$\mathrm{h}=10 \mathrm{~m}$. In this case, the point for $\mathrm{z}_{\alpha} / \mathrm{h}$ (i.e., $\mathrm{z}_{\alpha} / \mathrm{h}=0.12$ ) falls somewhat higher than the Raupach formulation on Figure 5, but the point for $d_{\alpha} /$ h (i.e., $d_{\alpha} / h=0.6$ ) is much closer to the Raupach formulation on Figure 6.

A comparison of the various roughness estimates for the Landes Forest is provided in Table 3. The values fall generally within the broad range of published values for other coniferous forests (e.g. Garratt, 1977, Jarvis et al., 1975 and Thom et al.,1975) that indicate $z_{\delta} / h$ to lie usually between 0.02 and 0.2 , and $d_{\alpha} / h$ mostly between 0.6 and 0.9 .

Although the region analyzed consists of over three quarters pine forest, the remaining part contains a mixture of agriculture and shrub patches. There was no information on vegetation type or structure in these patches except for fractional cover, and thus, they were included in the analysis assuming the same overall mean canopy similarity parameter, $\mathrm{N}=6.1$. Results indicate that both the pine and agriculture/shrub regions possess a wide range of roughness values. The computed roughness of the agriculture/shrub region yields a mean of about 0.081 and a standard deviation, $\mathrm{s}_{\mathrm{ZA}}=0.025$, whereas the forested mean was estimated to be 0.055 and the standard deviation, $\mathrm{s}_{\mathrm{ZF}}=0.013$. For the displacement height, the agriculture/shrub region possesses a mean of 0.71 and a standard deviation, $\mathrm{s}_{\mathrm{dA}}$ $=0.121$, while the forested portion possesses a mean of 0.82 and standard deviation, $\mathrm{s}_{\mathrm{dF}}=$ 0.061. The influence of agriculture/shrub on the roughness histograms of Figures 7 and 8 is illustrated by drawing arrows of one standard deviation about the mean for both pine and agriculture/shrub. Although variance in roughness is generally not available, the computed means for the two vegetation types are consistent with the published values (Brutsaert, 1982). 


\subsection{Sensitivity to fractional vegetation cover}

The sensitivity of the above formulation can be examined by rearranging Figures 5 and 6 in terms of fractional cover. Inserting Equation (15) for the particular Landes case with $\mathrm{N}=6.1$ directly into (3) and (5), and again applying Raupach's global values for the constants, yields plots of $z_{\alpha} / h$ versus $m$ and $d_{\alpha} / h$ versus $m$ for the Landes Forest, shown in

Figures 9 and 10, respectively. Figure 9 indicates that the greatest sensitivity of zo/h occurs at the lowest values of $m$, less than about 0.15 . At about $m=0.25, \mathrm{z}_{\mathrm{o}} / \mathrm{h}$ reaches it peak at this theoretical point where the flow begins to skim over the canopy. For $m$ greater than $0.25, \mathrm{z}_{\mathrm{d}} / \mathrm{h}$ is relatively insensitive to the fractional cover.

\subsection{Scale limitations}

The scales to which the frontal and canopy area parameterizations are valid are difficult to quantify, although the following guidelines must be met. They apply where the spatial distribution of the vegetation cover is statistically homogeneous and of one general geometric shape at the subpixel level. Thus, the upper limit of the satellite pixel scale for which they are applicable is variable and site specific, highly dependent on the large-scale spatial distribution of a given vegetation type. The lower limit depends on the relative scale of the pixel as compared to the scale of the individual canopy frontal area, as it is necessary to insure a statistically significant number of canopies within the pixel. A suitable lower limit criterion that meets that objective is $A_{p} / v A_{t} \gg 10$. 


\section{Conclusions}

The theoretical parameterizations presented herein for the frontal and canopy area indices of random plants provide a mechanism for estimating local aerodynamic roughness over flat terrain, in terms of fractional vegetation cover observed from nadir-viewing satellite sensors. The formulations, graphically displayed in Figure 2 in terms of the nondimensional similarity parameter, are general and theoretically can be applied to any natural vegetation of Poisson distribution, not only coniferous forests. The fractional cover estimates required in the formulations can be obtained from any source, satellite based approaches or other gridded or non-gridded datasets.

When incorporated into Raupach's formulas and applied to the Landes Forest test case near Lubbon during HAPEX-Mobilhy, the roughness estimates compare reasonably well to reference values determined from field measurements taken during the experiment at the time of the satellite observation. They also fall within the range of roughness for coniferous forests. The limitations to the present analysis is that it applies to vegetation roughness, and the superposition of vegetation on topographic roughness is not addressed. Also, the ability of the parameterizations for frontal area to account for within-tree leaf density needs to be investigated.

Overall, however, the good agreement between the theoretical and experimental estimates for the Landes Forest case warrants further testing on other natural vegetated systems, forested and non-forested. While satellite remote sensing can not replace direct field measurements, the above approach may be suitable in natural vegetated regions when there exists only limited ground truth. 


\section{Acknowledgments}

The authors thank Ms. Becky Reifenstahl, NASA Goddard Space Flight Center 1997 summer intern student from Pennsylvania State University, for contributing to the calculations. Thomas Schmugge of the U.S. Department of Agriculture, Agricultural Research Service, provided the Landsat TM imagery and useful discussions on the Landes Forest. 


\section{References}

Andre, J.C., Goutorbe, J.-P. and Perrier, A., 1986. HAPEX-MOBILHY: A hydrologic atmospheric experiment for the study of water budget and evaporation flux at the climatic scale. Bull. Am. Meteorol. Soc. 67, 138-144.

Asrar, G., Myneni, R.B. and Kanemasu, E.T., 1989. Estimation of Plant-Canopy Attributes from Spectral reflectance Measurements. In: Asrar, G.(Ed.), Theory and Applications of Optical Remote Sensing. John Wiley and Sons, New York, pp. 252-296.

Asrar, G., Fuchs, M., Kanemasu, E.T. and Hatfield, J.L., 1984. Estimating absorbed photosynthetic radiation and leaf area index from spectral reflectance in wheat. Agronomy J. 76, 300-306.

Brutsaert, W., 1982. Evaporation into the Atmosphere. D. Reidel, Dordrecht, The Netherlands, $299 \mathrm{pp}$.

Brutsaert, W. and Sugita, M. 1992. Regional surface fluxes from satellite-derived surface temperatures (AVHRR) and radiosonde profiles. Boundary-Layer Meteorol. $58,355-366$.

Diggle, P.J., 1983. Statistical Analysis of Spatial Point Patterns. Academic Press, New York, 145 pp.

Franklin, J. and Strahler, A.H., 1988. Invertible canopy reflectance model of vegetation structure in semiarid woodland. IEEE Trans. Geosci. Remote Sens., GE-26, 809-825.

Garratt, J.R., 1977. Aerodynamic roughness and mean monthly surface stress over Australia. Division of Atmospheric Physics, CSIRO, Australia, Technical Paper No. 29, 19 pp. 
Gash, J.H., Shuttleworth, W.J. and Lloyd, C.R., 1989. Micrometeorological measurements in Les Landes Forest during HAPEX-Mobilhy. Agric. For. Meteorol. 46, 131-147.

Grell, G.A., Dudhia, J. and Stauffer, D., 1994. A Description of the Fifth-Generation Penn State/NCAR Mesoscale Model (MM5). National Center for Atmospheric Research (NCAR) Technical Note NCAR/TN-398+STR. 117pp.

Huete, A.R. and Lui, H.Q., 1994. An Error and Sensitivity Analysis of the Atmospheric- and Soil-Correcting Variants of the NDVI for the MODIS-EOS. IEEE Trans. Geosci Remote Sens., 32, 897-905.

Huete, A.R., 1988. A soil adjusted vegetation index (SAVI). Remote Sens. Environ. 25, 295-309.

Jarvis, P.G., James, G.B. and J.J. Landsberg, 1975. Coniferous Forest. In: Monteith, J.L. (Ed.) Vegetation and the Atmosphere, Volume 2 Case Studies. Academic Press, London, pp. 171- 240.

Jasinski, M.F., 1996. Estimation of subpixel vegetation density of natural regions using satellite multispectral imagery. IEEE Trans. Geosci. Remote Sens., 34, 804-813.

Jasinski, M.F., 1990a. Sensitivity of the Normalized Difference Vegetation Index to Subpixel Canopy Cover, Soil Albedo, and Pixel Scale. Remote Sens. Environ. $32,169-187$.

Jasinski, M. F., 1990b. Functional relation among subpixel canopy cover, ground shadow, and illuminated ground at large sampling scales. Proceedings of the SPIE Technical Conference on Remote Sensing of the Biosphere. International Society for Optical Engineering, Bellingham, pp 48-58.

Jasinski, M.F. and Eagleson, P.S., 1990. Estimation of subpixel vegetation cover using red-infrared scattergrams. IEEE Trans. Geosci. Remote Sens., 28, 253-267.

Kellerer, A.M., 1983. On the number of clumps resulting from the overlap of randomly placed figures in a plane. J. of Appl. Probability, 20, 126-135. 
Lettau, H., 1969. Note on aerodynamic roughness-parameter estimation on the basis of roughness element description., J. Appl. Meteorol. 8, 828-832.

Li, X. and Strahler, A.H., 1985. Geometrical Optical Modeling for a conifer forest canopy. IEEE Trans. Geosci. Remote Sens., GE-23, 705-721.

Mahrt, L., 1996. The bulk aerodynamic formulation over heterogeneous surfaces. Boundary-Layer Meteorology, 78, 87-119.

Mason, P.J., 1988. The formation of areally-averaged roughness lengths. Q.J. R. Met. Soc., 114, 399-420.

Monteith, J.L. and Unsworth, M. H., 1990. Principles of Environmental Physics, 2nd Edition, Edward Arnold, London, 291 pp..

Myneni, R.B., Asrar, G. and Kanemasu, E.T., 1989. The Theory of Photon Transport in Leaf Canopies. In: Asrar, G.(Ed.), Theory and Applications of Optical Remote Sensing, John Wiley and Sons, New York, pp 142-204.

Parlange, M.R. and Brutsaert, W., 1989. Regional roughness of the Landes Forest and surface shear stress under neutral conditions, Boundary-Layer Meteorol., 48,69-76.

Paeschke, W., 1937. Experimentelle Untersuchungen zum Rauhigkeits- und Stabilitatsproblem in der bodennahen Luftschicht. Beitrage z. Phys. d. frein Atmos. 24, 163-189.

Perry, C.R. and Lautenschlager, L.F., 1984. Functional equivalence of spectral vegetation indices. Remote Sens. of Environ. 14, 169-182.

Raupach, M. R., 1994. Simplified expressions for vegetation roughness length and zeroplane displacement as functions of canopy height and area index. Boundary-Layer. Meteorol. 71, 211-216.

Raupach, M. R., 1992. Drag and drag partition on rough surfaces. Boundary- Layer. Meteorol. 60, 375-395.

Ross, J., 1981. The radiation regime and architecture of plant stands, Dr. W. Junk Publishers, The Hague, 391 pp. 
Seginer, I. 1974. Aerodynamic roughness of vegetated surfaces. Boundary Layer Meteorol. 5, 383-393.

Shaw, R.H. and Pereira, A.R., 1982. Aerodynamic roughness of a plant canopy: a numerical experiment. Agric. Meterol. 26, 51-65.

Stull, R., 1988. An Introduction to Boundary Layer Meteorology, Kluwer, Holland, $666 \mathrm{pp}$.

Thom, A.S., Stewart, J.B., Oliver, H.R. and Gash, J.H.C., 1975. Comparison of aerodynamic and energy budget estimates of fluxes over a pine forest. Q. J. R. Meteorol. Soc. 101, 93-105.

Tucker, C.J., Vanpraet, C., Boerwinkel, E., and Gaston,A., 1983. Satellite remote sensing of total dry matter production in the Senegalese Sahel. Remote Sens. Environ., 14, 461-474.

Whittaker, R.H., 1975. Communities and Ecosystems, 2nd Edition, Macmillan Publishing Co., New York, 385.

Wooding, R.A., Bradley, E.F., and Marshall, J.K., 1973. Dray Due to Regular Arrays of Roughness Elements of Varying Geometry. Boundary Layer Meteorol. 5, 285-308. 


\section{Figure Captions}

Figure 1. Schematic figure of geometric canopy model for the particular case of plants represented as cones on a post with Poisson distributed plant centers. Plants are geometrically similar. Although varying in size, they possess the same basic shape and constant diameter to height ratio, $\mathrm{D} / \mathrm{H}$.

Figure 2. Canopy area index versus fractional cover for any Poisson distributed canopy. N is the canopy area similarity parameter, or the ratio of the total outside surface area of the canopy to the vertically projected area. Physically, large $\mathrm{N}$ represents tall plants with narrow canopies while small $\mathrm{N}$ represents short plants with wide canopies.

Figure 3. Frequency distribution of fractional vegetation cover, Landes Forest near Lubbon, June 23, 1986, based on Jasinski (1996).

Figure 4. Frequency distribution of canopy area index, Landes Forest near Lubbon, June 23, 1986. Distribution calculated by applying Equation (15) with $\mathrm{N}=6.1$ to the frequency distribution of fractional cover in Figure 3.

Figure 5. Normalized aerodynamic roughness versus canopy area index. Plot compares Raupach's (1994) theoretical formula with estimates from field data obtained over Landes Forest during HAPEX-Mobilhy in June 1986. Field data are plotted versus mean canopy area index estimated in the present study. Data from radiosounding analysis by Parlange and Brutsaert (1989) are plotted using actual tree height of $\mathrm{h}=20 \mathrm{~m}$ as well as their estimated effective tree height of $h=10 \mathrm{~m}$. 
Figure 6. Normalized displacement height versus canopy area index, Landes Forest near Lubbon, June 1986. Plot compares Raupach's (1994) empirical formula with estimates from field data obtained over Landes Forest during HAPEX-Mobilhy in June 1986. Field data are plotted versus mean canopy area index estimated in the present study. Data from radiosounding analysis by Parlange and Brutsaert (1989) are plotted using actual tree height of $\mathrm{h}=20 \mathrm{~m}$ as well as their estimated effective tree height of $\mathrm{h}=10 \mathrm{~m}$.

Figure 7. Frequency distribution of $z_{\mathcal{d}} / \mathrm{h}$, Landes Forest near Lubbon, June 1986, obtained by applying satellite derived canopy area index distribution of Figure 4 to Raupach's (1994) theoretical formulation. Arrow bars indicate one standard deviation of $z_{d} / h$ about its mean for the pine forest pixels, $\mathrm{s}_{\mathrm{ZF}}$ and the agricultre/shrub pixels, $\mathrm{sZA}_{\mathrm{ZA}}$.

Figure 8. Frequency distribution of $d_{\alpha} /$ h, Landes Forest near Lubbon, June 1986, obtained by applying satellite derived canopy area index distribution of Figure 4 to Raupach's (1994) theoretical formulation. Arrow bars indicate one standard deviation of $d_{o} / h$ about its mean for the pine forest pixels, $\mathrm{s}_{\mathrm{dF}}$ and the agricultre/shrub pixels, $\mathrm{s}_{\mathrm{dA}}$.

Figure 9. Normalized aerodymamic roughness versus fractional canopy cover. Results obtained in similar manner to Figure 5 except with abscissa converted to fractional cover, for the particular case of the Landes Forest near Lubbon, June 1986, where the mean canopy area index is estimated to be 6.1 .

Figure 10. Normalized displacement height versus fractional canopy cover. Results obtained in similar manner to Figure 6 except with abscissa converted to fractional cover, for the particular case of the Landes Forest near Lubbon, June 1986, where the mean canopy area index is estimated to be 6.1. 
Table 1. Summary of Canopy Geometry Similarity Formulas 1

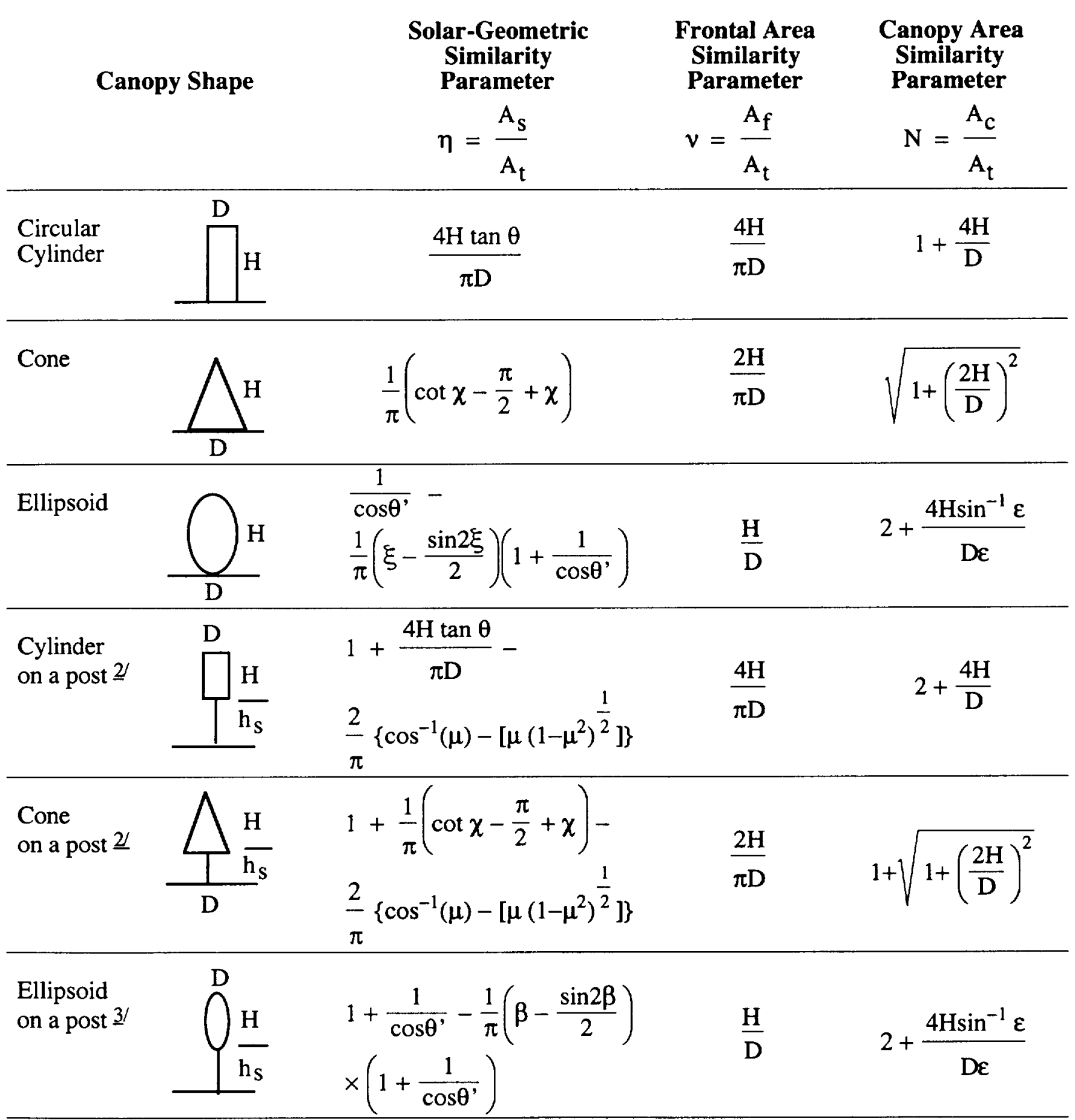

1/ Where $\mathrm{D}=$ maximim canopy width; $\mathrm{H}=$ canopy height; $\mathrm{h}_{\mathrm{s}}=$ height of post, $\theta=$ solar zenith angle; $\chi=\sin ^{-1}(\mathrm{D} / \mathrm{H} \tan \theta) ; \mu=\mathrm{h}_{\mathrm{s}}(\tan \theta) / \mathrm{D} ; \quad \beta=\cos ^{-1}\left\{\left[\left(1+\left(2 \mathrm{~h}_{\mathrm{S}} / \mathrm{H}\right)\right]\left[\left(1-\cos \theta^{\prime}\right) / \sin \theta^{\prime}\right]\right\} ;\right.$

$\theta^{\prime}=\tan ^{-1}[(\mathrm{D} \tan \theta) / \mathrm{H}] ; \quad \xi=\cos ^{-1}\left[\left(1-\cos \theta^{\prime}\right) / \sin \theta^{\prime}\right] ; \varepsilon=\left[1+(\mathrm{D} / \mathrm{H})^{2}\right]^{0.5}$.

2/ Assumes $\mathrm{D}<\mathrm{h}_{\mathrm{s}} \tan \theta$.

3/ Assumes $\mathrm{D}\left(1+1 / \cos \theta^{\prime}\right)<\left(\mathrm{H}+2 \mathrm{~h}_{\mathrm{s}}\right) \tan \theta$. 


\section{Table 2.}

Estimated site parameters for the Landes Forest near Lubbon, June 23, 1986.

Item (units)

Solar zenith angle (degrees)

Fractional canopy cover

Solar-geometric similarity parameter

Mean canopy diameter (m)

Mean canopy height (m)

Mean stem height (m)

Mean total canopy height, $\mathrm{H}+\mathrm{h}_{\mathrm{s}}(\mathrm{m})$

Frontal area similarity parameter

Canopy area similarity parameter

Mean Canopy Area Index
Symbol

$\theta$

m

$\eta$

D

$\mathrm{H}$

$\mathrm{h}_{\mathrm{s}}$

$\mathrm{h}$

v

$\mathrm{N}$

$\bar{\Lambda}$
Estimate

31.6

0.67

1.05

5.1

12.8

7.2

20.0

1.59

6.1

3.4 
Table 3.

Comparison of roughness lengths for the Landes Forest near Lubbon, June 23, 1986.

\begin{tabular}{|c|c|c|c|c|c|}
\hline Source & $\begin{array}{c}\text { Height } \\
(\mathrm{m})\end{array}$ & $\begin{array}{r}\mathbf{z}_{\mathbf{0}} \\
(\mathrm{m}) \\
\end{array}$ & $\begin{array}{l}\mathbf{d}_{\mathbf{0}} \\
(\mathrm{m})\end{array}$ & $\mathbf{z}_{\mathbf{O}} / \mathbf{h}$ & $\mathbf{d}_{\mathbf{o}} / \mathbf{h}$ \\
\hline Present study & 20 & 1.2 & 16.0 & 0.061 & 0.79 \\
\hline Parlange and Brutsaert (1989) & $101 /$ & 1.2 & 6.0 & 0.12 & 0.60 \\
\hline " & $20 \underline{2}$ & 1.2 & 6.0 & 0.06 & 0.30 \\
\hline Gash et al. (1989) & 20.3 & 1.9 & 15.2 & 0.094 & 0.75 \\
\hline
\end{tabular}




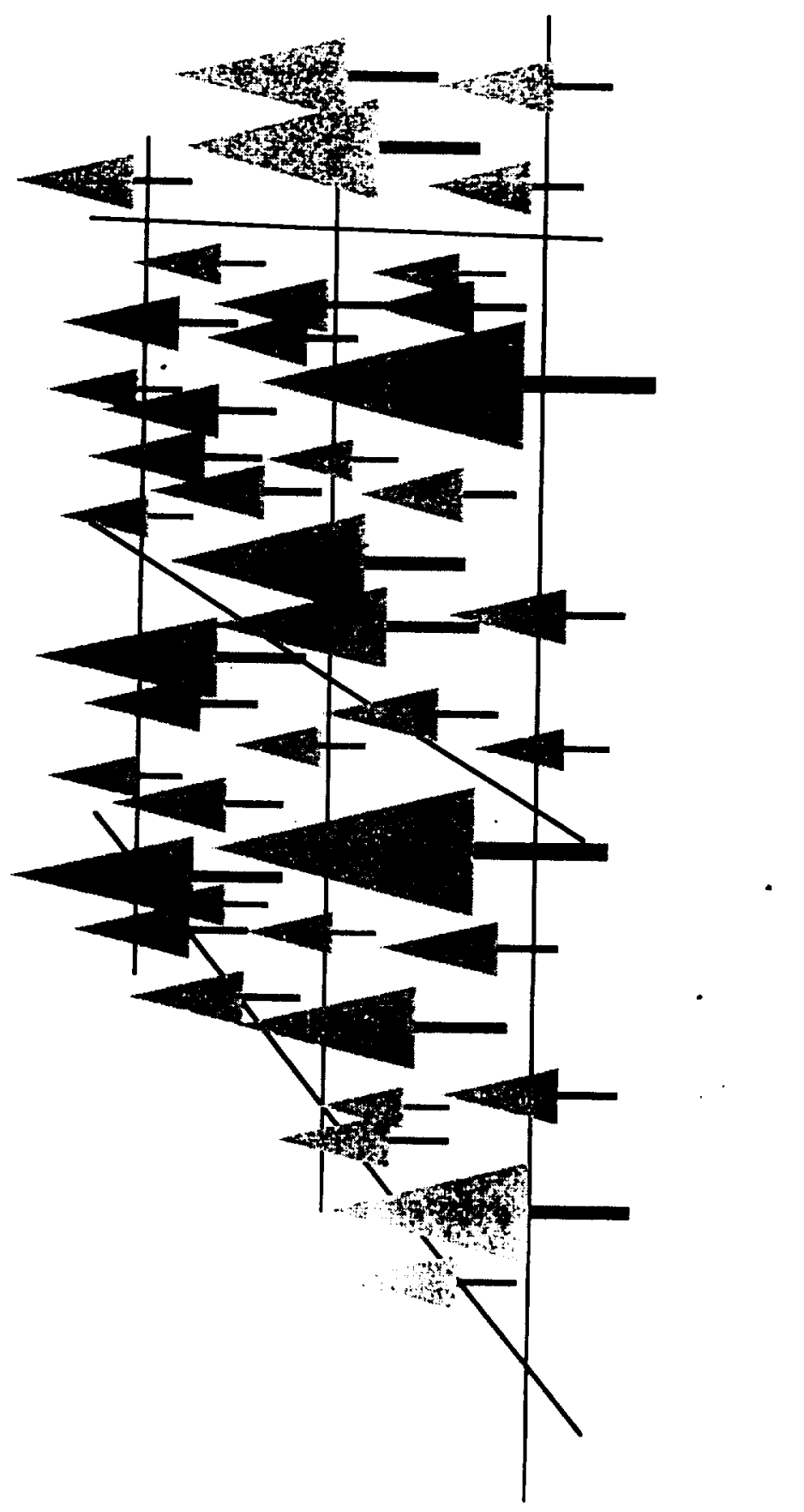

$\left.F_{q}\right)$ 


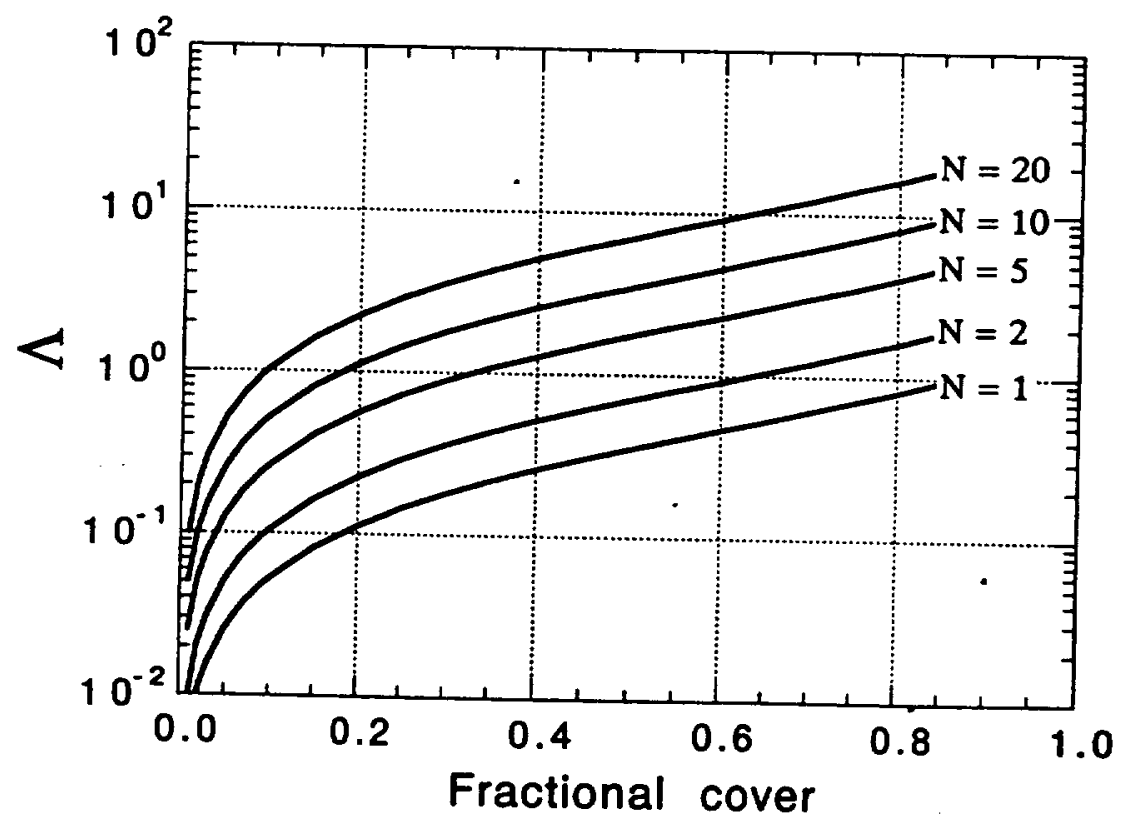




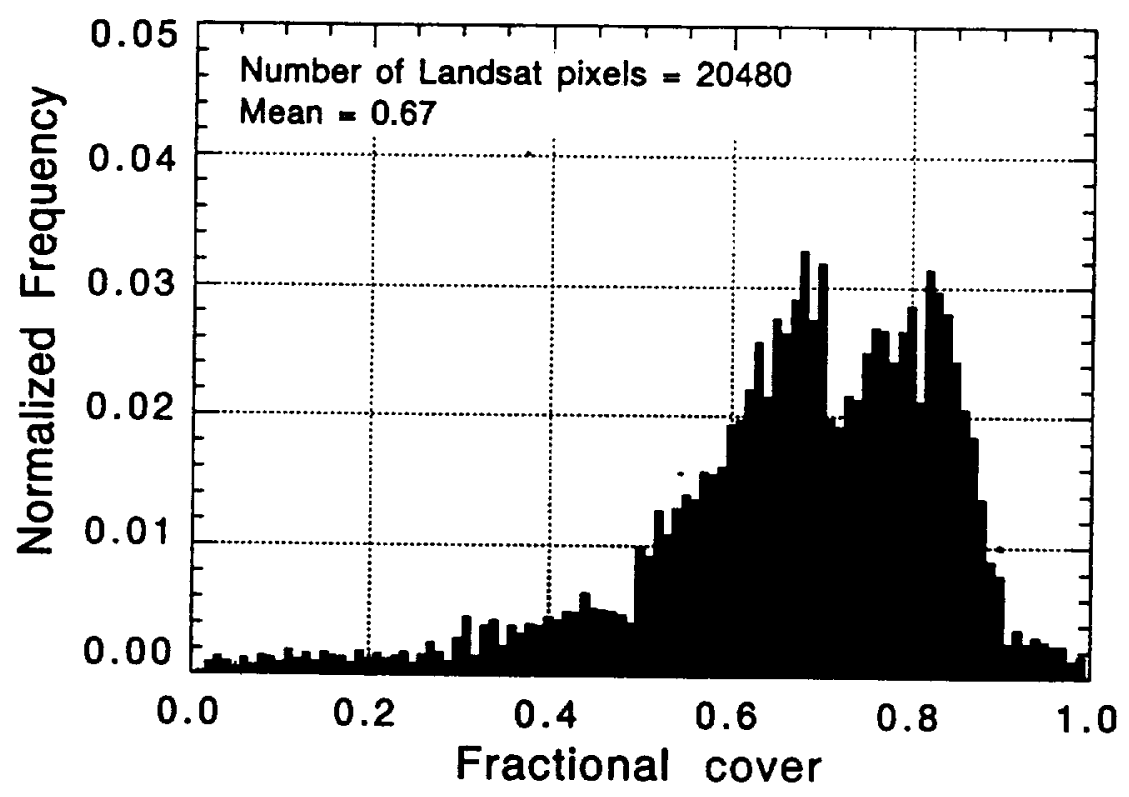

$f_{19} 3$ 


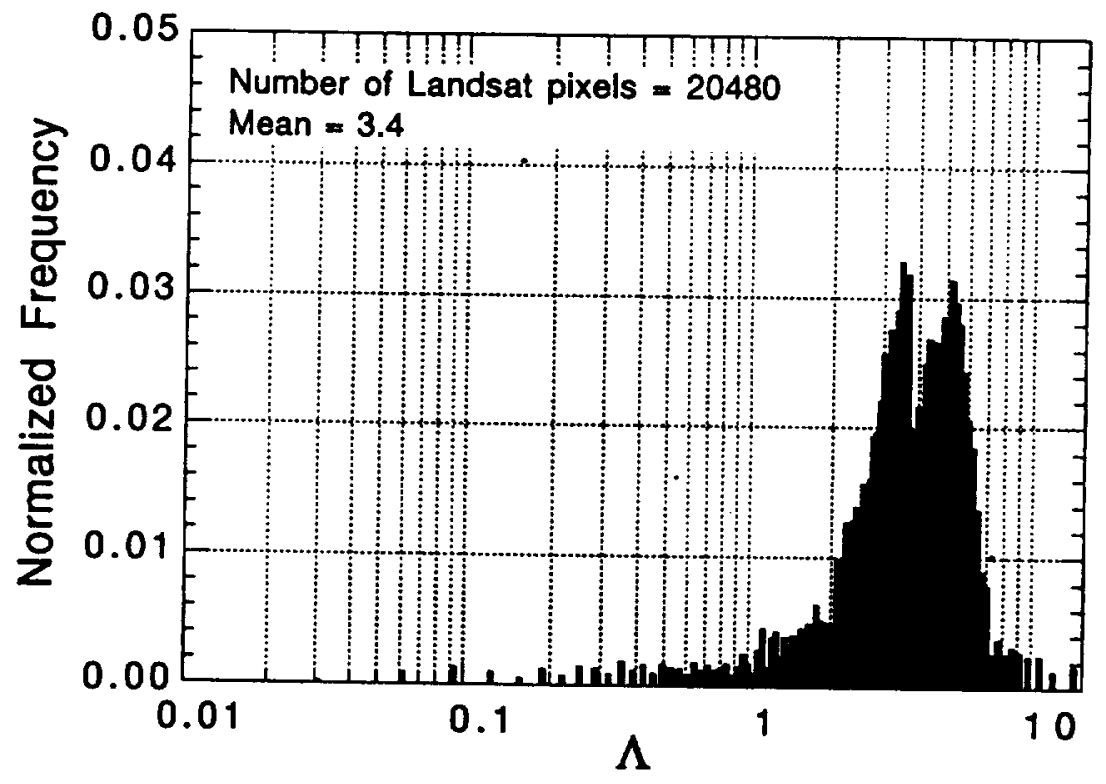

Fin $A$ 


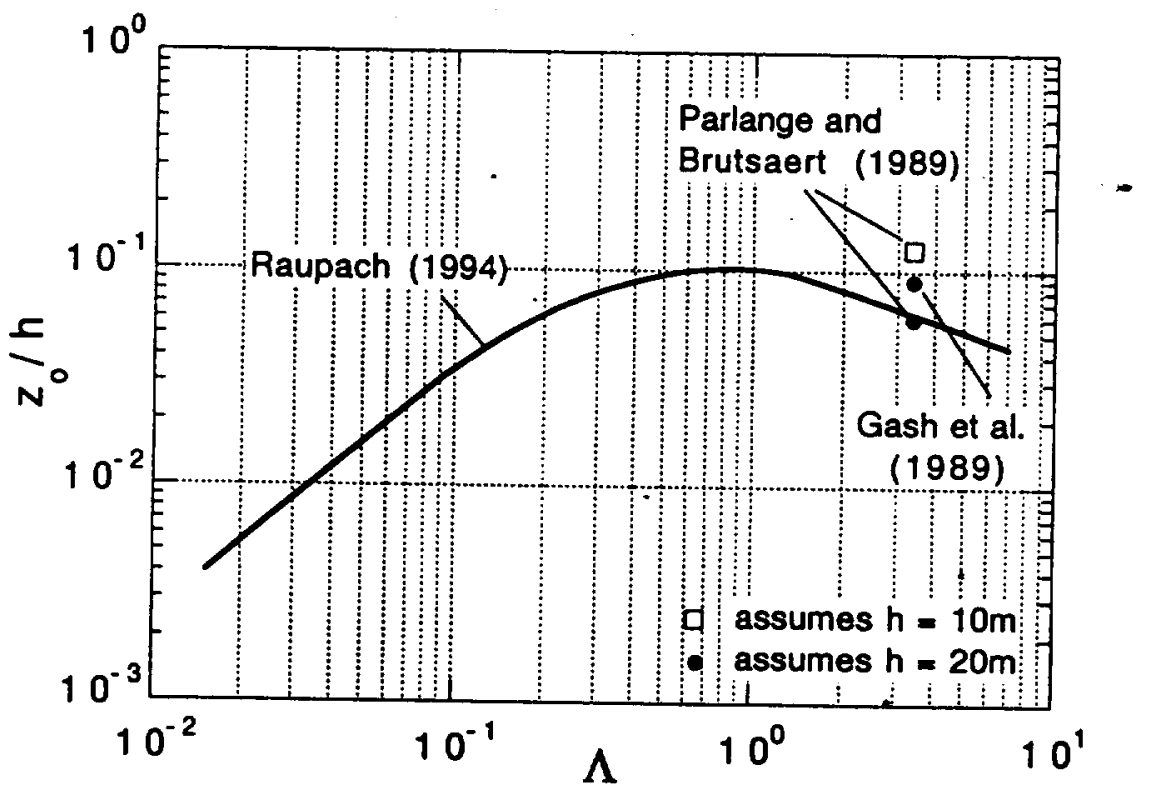

fin 5 


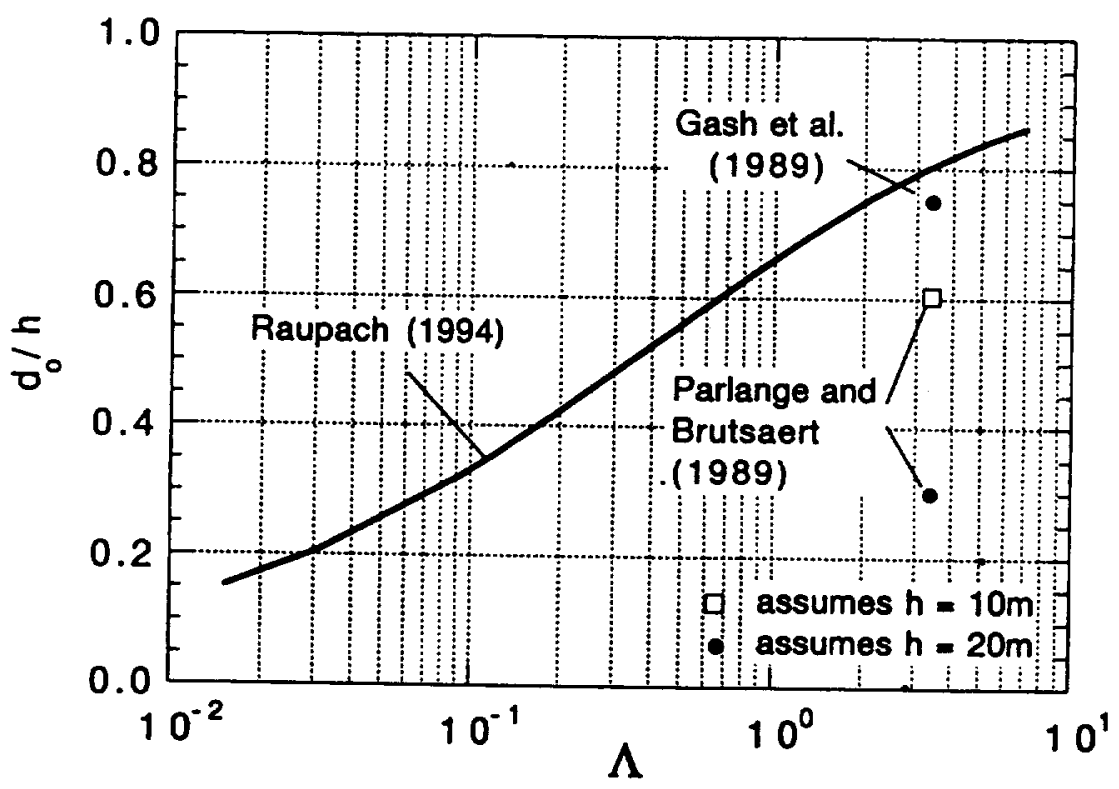

Fig 6 


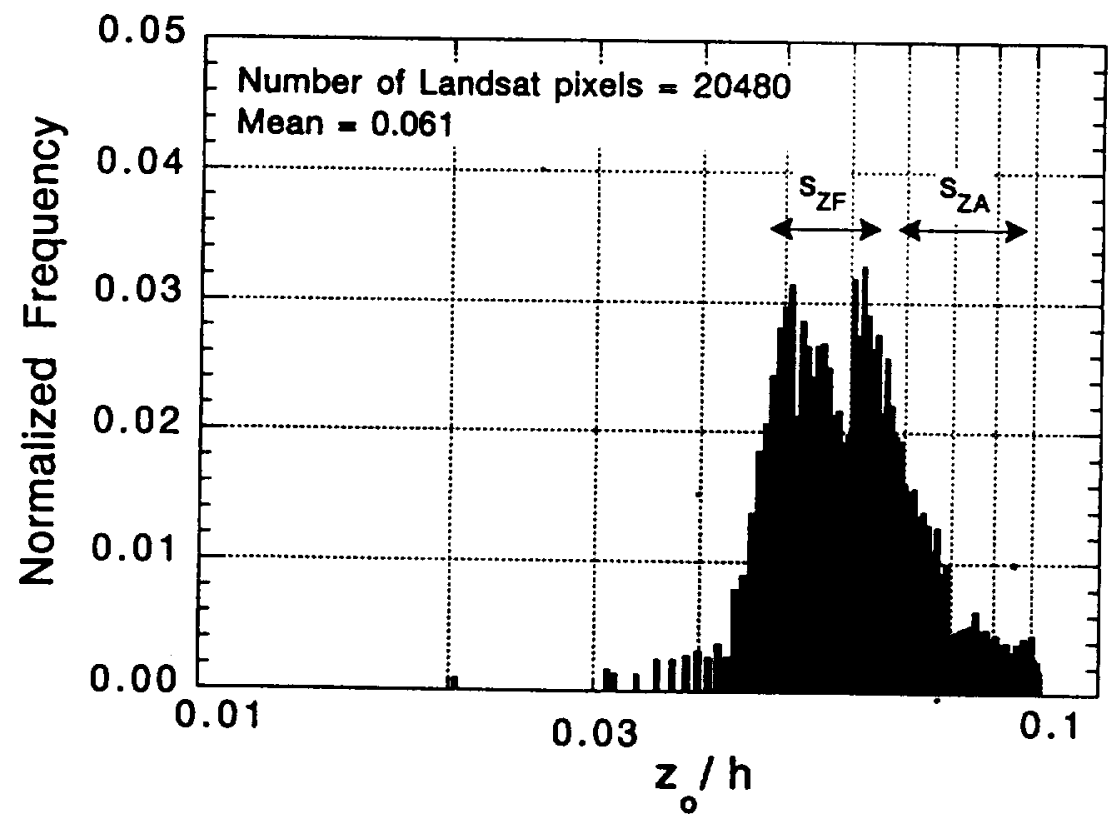

Fig 7 


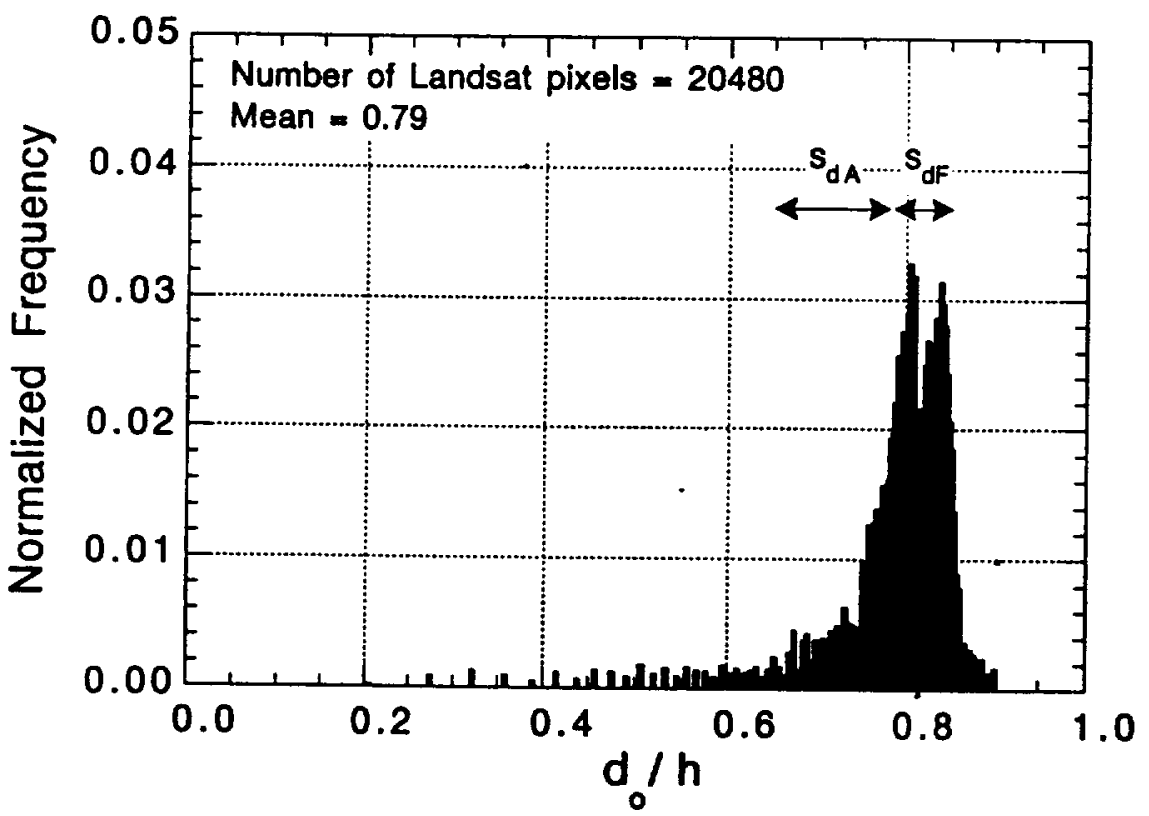

$f_{19} 8$ 


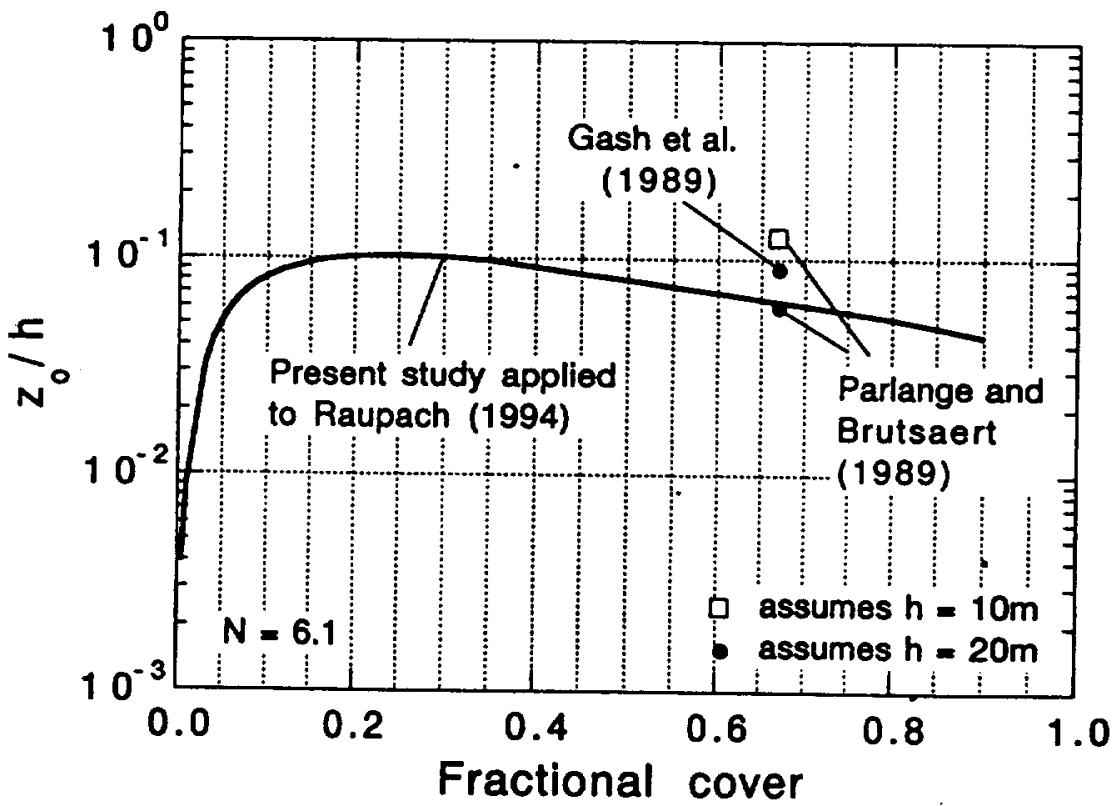

Fig 9 


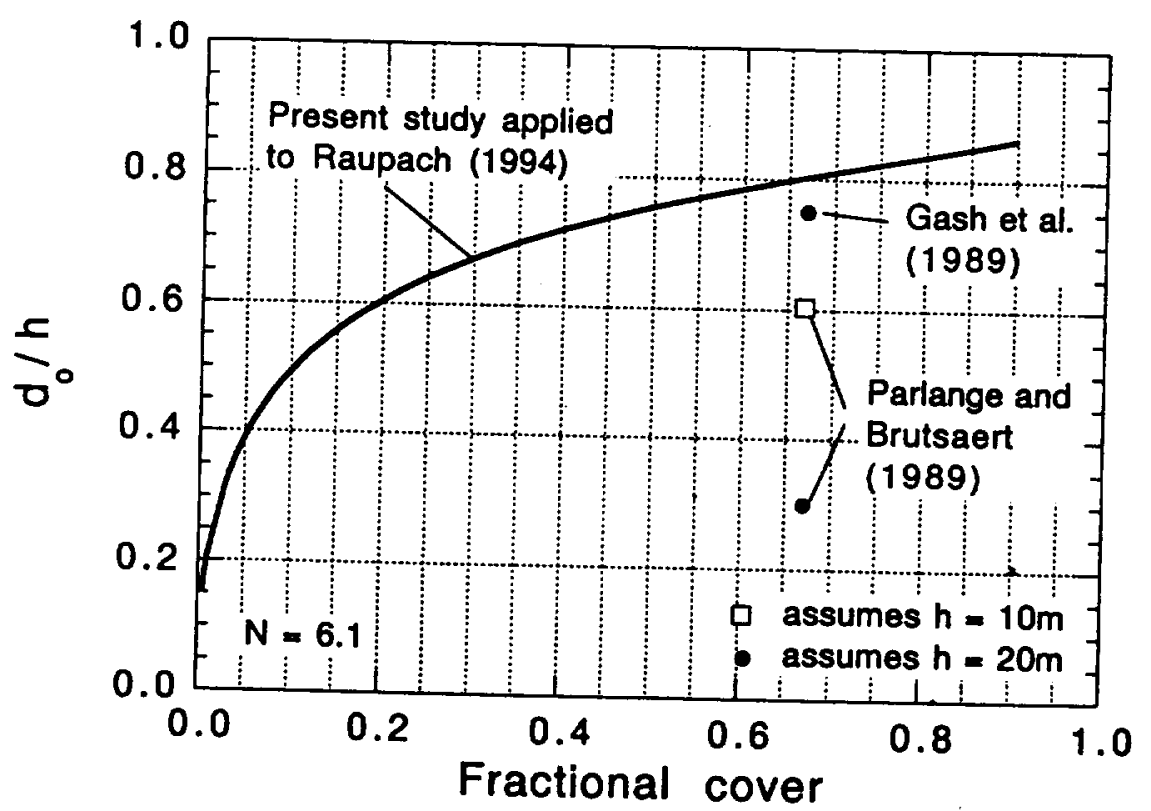

Fi, 10 